\title{
Legal status of man in the world of artificial intelligence development and sustainable development tendencies. Awareness in society
}

\author{
Evgeniya Savoschikova ${ }^{1,2, *}$, Tatiana Slyusarenko ${ }^{1}$, and Tatiana Alimpiyeva ${ }^{3}$ \\ ${ }^{1}$ Moscow University named after S.Yu.Vitte, Moscow, Russia \\ ${ }^{2}$ Russian State University of Tourism and Service (RSUTS), Moscow, Russia \\ ${ }^{3}$ Aktubinskiy Regional University named after K. Zhubanov, Aktobe, Kazakhstan
}

\begin{abstract}
The article raises issues of balance of modern tendencies of international community development on the basis of sustainable development and Artificial Intelligence (AI) development. It also raises issues of awareness levels of sustainable development processes and AI development in accordance with the human rights and status of the individual in the modern society. The study refers to data analysis of surveys among the students of Moscow Higher Education Institutions in such specialties as Jurisprudence, Economics, State and Municipal Management, Applied Informatics, for the research of awareness levels of development of international community within the framework of sustainable development and development of AI (artificial intelligence) in the context of human rights.
\end{abstract}

\section{Introduction}

In the theory of human rights the generally accepted thesis is recognition of human rights as the supreme value. Article 2 of the Russian Federation Constitution declares the given thesis.

Declaration of Independence of American colonies in 1776 declares the equality in rights and inherency of personal rights.

Such theses were "automatically" included into all fundamental documents of all countries in the world.

Article 1 of the Basic Law of the Republic of Germany guarantees the inviolability of human dignity and integrity and they are the norms of human activity in the community in any form.

Constitution of France, 5 Fructidor III in Declaration of Rights and Duties of man and citizen proclaims the rights equality, the basic rights inviolability of man and citizen.

The basic rights of people and enshrining of integrity and inviolability of human dignity are stated in the second Constitution of People's Republic of China.

In Australia the freedom of the individual and the inviolability of human dignity are stated in the laws " On Combating racial discrimination" (1975), "On Combating gender

\footnotetext{
* Corresponding author: jene30@mail.ru
} 
discrimination" (1984), “On the Human Rights Commission ” (1986),"On combating age discrimination" (2004).

Anyway, the standards of laws in different countries, including the Basic Laws, Constitutions, and Declarations proclaim inviolability, as the minimum of basic rights and freedom and human dignity protection.

However, the tendencies and strategies of international community development focus on sustainable development. How sustainable development tendencies and human rights and their values are combined as recognizable achievement and values of human community.

The concept of sustainable development declares theses in interpretation of 4 indices of sustainable development, supposing, in our view, cardinally opposing tendencies which demand possible human rights restrictions and understanding that it is the part of biosphere. In 1992 UNO set up a special Committee on sustainable development. In 1995 The Committee accepted the Action Plan on indices of sustainable development. It was designed for the countries to use on the national level during making decisions on development of the country. In Declaration of 1992 (Rio de Janeiro) the creators of international standards assigned 5 main contradictions of sustainable development: where the point about people living in harmony with nature, and a man is in the center of attention as the way out from controversial situation between real life and harmonious life with nature. The understanding of the balance necessity doesn't prevent national law makers from possible errors and enforcement practice. "Imbalances" in excessive restrictions are not excluded and they occur.

On the other hand, human society development is connected with unconscious restrictions and dangers of AI development and it was repeatedly emphasized by the scientists in their papers including legal scholars. AI, its development and implementation change the modern society and a man. As an example, the experience of ekzo prosthetic device can be used. It gives a man more possibilities than the parts of the body a man has got by nature, it cannot help but change the consciousness of a person who uses ekzo.

It is a single example, though there are a lot of dangers there.

500 leading specialists in Computing and futurologists have participated in large-scale study conducted by Pew Research Center and 5 significant problems to which AI leads have been put. (Anderson et al, 2018):

1. The use of AI decreases people's control over their lives;

2. The system of observing and data collecting for providing AI effective work as well as getting profit is dangerous.

3. Displacement of people's working places by AI strengthens economic and digital gap and leads to social upheaval.

4. Cognitive and social skills will be lowered so people will depend on AI.

5. People will face with digital vulnerability (cybercrimes and cyber wars) and the possibility of information usage as a weapon.

Contrary to prevailing opinion that AI won't necessarily become obligatory democratizing force but it will increase the power and wealth of those who own them. The use of AI increases the current gap between wealthy people and the rest. It is connected with the development of AI which is very expensive and requires the specialists with particular knowledge and skills.

Besides the more data AI has, the better it is and the purchase of data is rather expensive especially the personal data which are the most valuable. This is the key difference of AI from network technologies. The advantages of access to which were widely distributed whereas the prices on the components were fallen fast for all. (Dignam, 2020)

At this stage of AI development and in its foreseeable future software algorithms, though complex cannot be considered as responsible entity.

Sooner or later any decision of AI will lead that the person will suffer moral and physical harm. And at this moment the question will raise -who is responsible for? And the answer 
to this question has to be given before there is the necessity in it. IF AI algorithm makes a mistake, who will be responsible for it? And if the question is raised globally- what is AI and how has it to be taken by the society? If the machines can imitate emotions and act as people do how they should be operated? Should machines be considered as people, animals or inanimate objects? What is the level on which we ascribe responsibility, responsibility to technologies and machines in comparison to people, who allegedly control them? At first sight it seems like it is early to ask such questions but it's not.

In March, 2018 a self-driving car UBER hit and killed a pedestrian. The people were outraged by the fact that the car killed the man and demanded punishment of those responsible (NY Times, 2018). Thousands of people continue to be killed in car accidents because of a man. What is the main reason of social outrage?

The human society cannot accept people's death by car. However, the probability of elimination of all dead in car accidents almost certainly to be zero. If we want to have selfdriving cars, this story will repeat again and again. That's why we have to ask these questions, defining the boundaries and limits of AI ethics, making laws and decisions now to protect ourselves from future tragedies.

It is this aspect which the scientists are trying to identify developing AI ethics. Justice, accountability, sustainability and transparency are the principles aimed to fill gaps between intellectual capacities of machines and its fundamental lack of moral responsibilities.

Although the further AI use is inevitably, the fact that AI is a product of human activity and informed designers' decisions is often ignored. It is people mainly implement technology development on different levels and by different methods. As a result there are many restrictions both in creating $\mathrm{AI}$ and controlling. Not the least is the high discriminatory potential of AI.

Particular important are decisions of limited resources allocation, for instance, when algorithms results assist to choose the limited number of scholarship applicants, grants and funding. It is important to understand that AI can make mistakes and make wrong decisions because of algorithms restrictions. For instance, algorithm may refuse to accept a scholarship application if the average score is 4, 49 while limiting is 4, 5. In order to make adjustments and make informed decisions the employees have to understand how exactly AI system works.

It's obvious that the simpler algorithm the easier to explain it, but the complicated algorithms can be more accurate or less preconceived.

There is the necessity of sustainable development balance + human rights + AI, it requires civilized legal regulation, new programs developing in different specialties and directions for getting competence. Within these processes it is important to aware and understand the new forms of relationships appearing in the society and understand the people's level of awareness on assigned strategic issues.

\section{Materials and methods}

The survey method is used in the study as a widely used method of collecting the initial information. The given method assumes practical use especially in humanitarian area. We'll use this method in our study for understanding the people's level of awareness and their involvement to the supposed tendencies of development of state of law and the entire world's community.

The survey is conducted internally, in groups and focused on concrete theme.

It is necessary to understand the concept of sustainable development. It is worth drawing attention to youth, having certain level of training in the area of Jurisprudence, Economy and Information Technology. 
The students from Moscow Institutes of Higher Education who study Jurisprudence, Economy, State and Municipal Management and Applied Informatics have participated in the survey.

\section{Results}

450 respondents were surveyed on issues of sustainable development.

Table 1. Understanding sustainable development.

\begin{tabular}{|c|c|}
\hline $\begin{array}{c}\text { Do you know anything about sustainable } \\
\text { development? }\end{array}$ & $\begin{array}{c}48 \% \text { of respondents have heard about it. } \\
27 \% \text { have heard, but not interested in it. } \\
25 \% \text { take an active interest }\end{array}$ \\
\hline $\begin{array}{c}\text { What aims of SD (sustainable development) } \\
\text { are the most actual for Russia and your } \\
\text { region? (Moscow oblast and Moscow city) }\end{array}$ & $\begin{array}{c}50 \% \text { have pointed out SD as an important } \\
\text { factor for poverty eradication, social problems } \\
\text { solution }\end{array}$ \\
& $\begin{array}{c}34 \% \text { - sustainable economic growth and } \\
\text { healthy lifestyle provision. } \\
16 \% \text { of respondents point out that gender } \\
\text { equality fight against climate change and } \\
\text { rational models of consumption and } \\
\text { production are the most significant objectives } \\
\text { of sustainable development. }\end{array}$ \\
\hline $\begin{array}{c}\text { Are the restrictions of human rights towards } \\
\text { sustainable development in Russia possible? }\end{array}$ & \begin{tabular}{c} 
Yes, possible - $44 \%$ of responds \\
\hline
\end{tabular} \\
\hline
\end{tabular}

Concerning $\mathrm{AI}$ in the same representative group of respondents:

1. $89 \%$ of respondents know about AI technologies;

2. $58 \%$ of respondents know the areas of AI usage;

3. $29 \%$ of respondents can't explain what $\mathrm{AI}$ is;

4. $48 \%$ of respondents are positive to the use of $\mathrm{AI}$;

5. $5 \%$ of respondents are negative to AI.

The human rights within the context of sustainable development

Does SD impact the human rights as a concept and development of new technologies with a view to AI?

More than $90 \%$ of respondents have replied affirmatively.

What are the forms and types of impacts of SD and AI on the human rights?

$35 \%$ of respondents can explain.

Answering the question of AI readiness to it in the Russian society and state you can apply to the report of AI Readiness Index 2020, by Oxford Insights and International Research Development Centre (IDRC), which provides the most complete information on this issue, divided into 3 main categories and 9 subcategories: (Vision, Management and Ethics, Digital Implications), Data and Infrastructure (Data Representativeness, Data Accessibility, Infrastructure) and Technology Sector ( Flexibility, Sector volume; Innovation Potential)

General index in rating of Russia is 60.85 from $100 \%$ and it takes 33 place among 172 participants in the world. But at the same time it takes the fifth place in the Eastern Europe, but the second key- subcategory "Responsible Use of AI" has got only 39,12\%, which put Russia into penultimate place according to this index in the ranking. The results are shown below. 


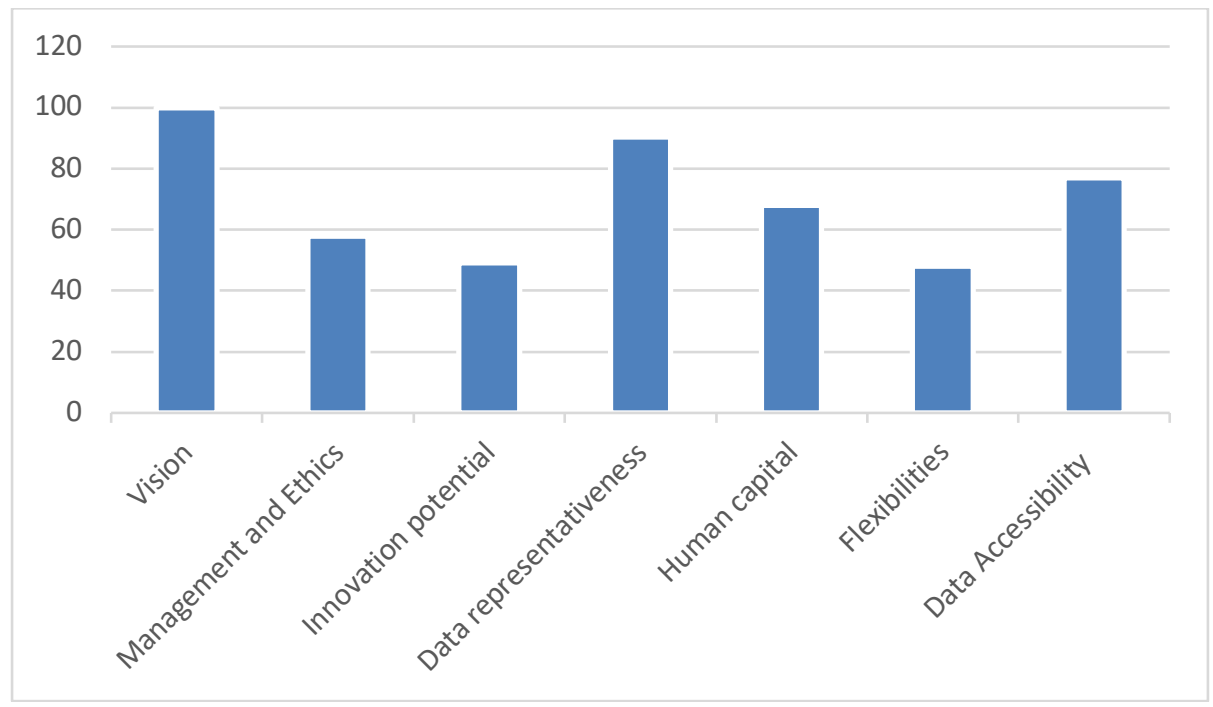

Fig.1. The level of readiness in using AI in Russia.

At drawing 1 extremely high indices of Vision, Data Representativeness and Accessibility attract attention.

Vision reflects the existence of a set of measures, fixed at the legislative level, providing AI development, approbation and implementation. It is necessary to point out the Decree of the President of the Russian Federation from 2019, 10, September, which approved the National Strategy of AI development for the period till 2030.

\section{Discussion}

$\mathrm{SD}+$ human rights $+\mathrm{AI}$ :

The issue on forms and character of impact of sustainable development and AI on human rights have met some difficulties. The students couldn't detail and explain it but the students studying at Applied Informatics could explain better the working processes and developing $\mathrm{AI}$, but the process of $\mathrm{AI}$ impact on the individual and citizen give rise to some perplexities. On the other hand, students of economic- juridical specialties could not explain the processes of AI creating.

Taking into account that the students of Moscow Institutes of Higher education who study Jurisprudence, Economics, State and Municipal Management, Applied Informatics have participated in the survey, in our view, introduction of new specialized subjects is required. They will allow the students to develop both within modern tendencies of society and state forming and implement general competence in forming the personality of specialists of high level of awareness. Moreover, it is necessary to introduce a multi-disciplinary approach for forming informed and competent specialists. Forming such specialists meet the modern tendencies of state and society development and comply with multi-disciplinarity.

In general, there is the necessity of popularization, accurate and competent explanation of SD, AI issues among the wider population. It allows forming conscious society which understands the tendencies of world's development free of affects targeted provocations and ignorance.

At present the modern society is faced with a certain stage when, on the one hand, we get to the boundaries defining the possibilities of AI self-development, and the necessity of 
competent society which is able to think on "a big scale" with a lot of options to solve problems, on the other hand.

Solutions of problems at the modern stage:

Accepting and understanding the level of society development and responsibilities of managerial systems in the state it is necessary to accept a normative framework with a regulative system of taking decisions with the help of AI at the federal legislation. It is an issue however which requires introduction of AI regulation exclusively placed under the authority of the Russian Federation.

The same system of AI development requires introduction of subjects contributing to critical thinking development.

Besides this, in April 2020 the Federal Law 24N123- Ф3 "On making experiments on special regulation lay down with a view to make necessary conditions for development and introduction of AI technologies in the city of federal significance Moscow and making amendments to Article 6 and 10 of Federal Law "On personal data", which makes experiments in providing to Moscow companies which deal with AI, anonymous personal data to stimulate the growth of $\mathrm{AI}$ in the private sector.

Although, the market volume index is still low, whereas it is concentrated in Moscow and its suburbs, and the majority of AI enterprises work either to governmental orders or to export. Market domestic request on AI development and adaptation is very low.

The average indices of Infrastructure and Flexibility demonstrate the existence of digital break, which can make collecting representative data difficult and make them not available due to the state aggressive policy on data collecting. It allows restraining the data quality, but, correspondingly, decreases the ethics of management. In the opinion of rating compilers, the Russian state exercises alarm level of state control over digital infrastructure.

The high indices in the index of human capital are due to high quality and education accessibility in STEM - subjects, and the fall of indices of innovation potential, in comparison with "brain drain" and it is a constant problem for Russia, because leading Russian scientists and technical specialists regularly leave the country for the West. But at the same time, exactly, in the area of state management the level of employee's readiness in using AI is rather low.

\section{Conclusions}

On issues of Sustainable Development:

The representative group of students from Russian higher education institutions shows the results comparable with the reactions of Russians in general. In April Centre of expertize and integral models conducted a survey of 1000 respondents from different regions of Russia. The views of our representative group and all Russians differ from global ones. They are less worried about ecology, climate, more actual are economic and social factors.

The least of all worries is global partnership.

On Issues of AI:

The most dangerous things are the lack of understanding "guarantees of the correct result because of mistakes of AI activity" and little knowledge in this area. It is necessary to develop the system of determination the degree of independence in making decisions in order to control the quality of taken decisions. 


\section{References}

1. The Constitution of the Russian Federation (adopted by popular vote on December 12, 1993), Official Internet portal of legal information, Rossiyskaya Gazeta, 144 (2020). Access mode: www.pravo.gov.ru

2. On conducting an experiment to establish special regulation in order to create the necessary conditions for the development and implementation of artificial intelligence technologies in the constituent entity of the Russian Federation - the city of federal significance Moscow, Federal Law of April 24, 2020 № 123-FZ, Collected Legislation of the Russian Federation of April 27, 17 (2020)

3. On the development of artificial intelligence in the Russian Federation. Decree of the President of the Russian Federation of October 10, 2019 № 490, Collected Legislation of the Russian Federation of October 14, 41 (2019)

4. AI Readiness Index 2020, Oxford Insights и International Research Development Centre (2020). Access mode: https://www.oxfordinsights.com/government-ai-readiness-index$\underline{2020}$

5. C. Alexopoulos, Z. Lachana, A. Androutsopoulou, V. Diamantopoulou, Y. Charalabidis, M. A. Loutsaris, How machine learning is changing e-government, 12th international conference on theory and practice of electronic governance (2019)

6. J. Anderson, L. Rainie, A. Luchsinger, Artificial Intelligence and the Future of Humans, Pew Research Center (2018)

7. A. Ben Rjab, S. Mellouli, Smart cities in the era of artificial intelligence and internet of things: literature review from 1990 to 2017, 19th annual international conference on digital government research: Governance in the data age, Delft, the Netherlands (2018)

8. Y. K. Dwivedi, L. Hughes, E. Ismagilova, G. Aarts, C. Coombs, T. Crick, ..., A. Eirug, Artificial intelligence (AI): Multidisciplinary perspectives on emerging challenges, opportunities, and agenda for research, practice and policy, International Journal of Information Management, 101994 (2019). Access mode: http://doi.org/10.1016/j.ijinfomgt.2019.08.002

9. P. Bentley, The three laws of artificial intelligence: Dispelling common myths. Should we fear artificial intelligence, SFU, 6-12 (2018)

10. N. Bostrom, E. Yudkowsky, The ethics of artificial intelligence, The Cambridge Handbook of Artificial Intelligence, 1, 316-334 (2014)

11. Yu. I. Leibo, Constitutional law of foreign countries (2012)

12. A. Dignam, Artificial intelligence, tech corporate governance and the public interest regulatory response, Cambridge Journal of Regions, Economy and Society, 13(1), 3754 (2020) 